\title{
TUMOR ESTROMAL GASTROINTESTINAL (GIST): FORMAS DE PRESENTACION
}

Drs. Roberto Oyanedel $Q^{(1)}$, Andrés O’Brien $S^{(1)}$, Alejandra Pizarro $G^{(2)}$, Elizabeth Zamora $E^{(1)}$, Christine Menias $O^{(3)}$.

1. Departamento de Radiología. Facultad de Medicina. Pontificia Universidad Católica de Chile.

2. Servicio de Radiología. Clínica Santa Maria. Santiago. Chile

3. Mallinckrodt Institute of Radiology. St. Louis, Mo, USA.

\begin{abstract}
Gastrointestinal Stromal Tumors (GIST) are rare tumors, accounting for less than $3 \%$ of gastrointestinal neoplasms, however, they are the most frequent mesenchymal tumors of the Gl tract. All GISTs are defined by the expression of CD117, a tyrosine kinase growth factor receptor, as opposed to other tumors like leiomyomas, leiomyosarcomas and neurogenic tumors. $70-80 \%$ are benign, and the majority is located in the stomach and small bowel, but also they can arise from any portion of the GI tract as well as from the mesentery, omentum and retroperitoneum. Malignant GISTs are usually large $(>5 \mathrm{~cm})$, with high mitotic index, and can metastasize to the liver and peritoneum.

CT findings that suggest GIST are: exofitic mass arising from bowel wall, well-circumscribed, that can present hemorrhage, necrosis and/or cystic component, and rarely is associated with bowel obstruction. Treatment is surgical resection. Therapy with tyrosine kinase inhibitor STI571 is promising.
\end{abstract}

Key words: Gastrointestinal tumor, Stromal tumor.

Resumen: El tumor estromal gastrointestinal (GIST) representa menos del 3 \% de las neoplasias gastrointestinales; sin embargo, es el tumor mesenquimatico mas frecuente del tracto digestivo. GIST se define por la expresión de un receptor de factor de crecimiento de tirosina kinasa, CD117, lo que lo diferencia de los otros tumores mesenquimáticos como leiomiomas, leio-miosarcomas, leiomioblastomas y tumores neurogénicos, que no expresan esta proteína. $70-80 \%$ de los GISTs son benignos, localizándose la mayoría en estomago e intestino delgado (> 90\%). Pueden originarse también de cualquier porción del tracto digestivo, así como del mesenterio, omento y retroperitoneo. GISTs malignos son generalmente de gran tamaño (> a $5 \mathrm{~cm}$ ), con

Oyanedel R, y cols. Tumor estromal gastrointestinal (GIST): Formas de presentacion. Rev Chil Radiol 2005; 11: 13-18.

Correspondencia: Dr. Andrés O’Brien.

obrienandres@yahoo.com índice mitótico alto, y puede metastizar a hígado y peritoneo. Hallazgos sugerentes a la tomografía computada (TC) son: masa exofitica que se origina de la pared del estomago o intestino, bien delimitada, que puede presentar hemorragia, necrosis o componente quístico, raramente asociada a obstrucción. El tratamiento es la resección quirúrgica. Se han descrito buenos resultados con inhibidor de tirosina kinasa STI571.

Palabras clave: Tumor estromal, Tumor gastrointestinal.

\section{Introducción}

El Tumor Estromal Gastrointestinal (GIST) es la neoplasia mesenquimatica más común del tracto digestivo; sin embargo su frecuencia representa solo un 0.1 a $3 \%$ de las neoplasias gastrointestinales. Anteriormente, eran clasificados como leiomiomas, leiomiosarcomas, leiomioblastomas, schwannomas o neurofibromas del tracto digestivo ${ }^{(1)}$. Sin embargo, la observación en el año 1983, que los GISTs expresaban en los estudios inmunohistoquimicos un receptor para el factor de crecimiento de la tirosina kinasa, llamado CD117 en un $100 \%$ de los casos, y la proteína CD34 en el $70 \%$ de los casos, estableció la diferencia con los tumores mencionados. Otros posibles marcadores tumorales incluyen vimentina, actina, proteína S-100 y desmina.

Los GISTs se originan de una célula precursora común, la célula intersticial de Cajal o marcapasos intestinal, o bien de una célula troncal más primitiva de la cual derivan la célula de Cajal y las células musculares lisas ${ }^{(2)}$.

Se pueden localizar en cualquier parte del tracto gastrointestinal, así como también en omento, mesenterio o retroperitoneo.

Un $70 \%$ se ubican en estómago(4), un 20 $30 \%$ en el intestino delgado y un $7 \%$ en la región anorrectal. A diferencia del resto del tubo digestivo, en el esófago los leiomiomas son más frecuentes.

El $70-80 \%$ de los GISTs son benignos. Hallazgos sugerentes de malignidad son localización extragástrica, tamaño superior a $5 \mathrm{~cm}$, un alto 
índice mitótico en el estudio histopatológico y la presencia de metástasis hepáticas o peritoneales. Raramente se asocia a adenopatías mesentéricas o retroperitoneales.

\section{Clínica y patología}

Por lo general los GISTs afectan a pacientes mayores de 50 años y pueden ser descubiertos en forma incidental. Algunas manifestaciones clínicas son hemorragia digestiva ya sea melena o hematoquezia, dolor abdominal, masa palpable, baja de peso, nauseas y vómitos ${ }^{(3)}$. Ascitis es un hallazgo poco común, al igual que la obstrucción intestinal.

Los GISTs tienen una mayor prevalencia en pacientes con Neurofibromatosis I y pueden ser múltiples, también forman parte de la tríada de Carney que se caracteriza por: Leiomiosarcoma en la antigua clasificación, paraganglioma y condromas pulmonares.

La patología demuestra un compromiso de la muscular propia de la pared intestinal, con crecimiento exofitico hacia la cavidad abdominal y abombamiento submucoso. En un $50 \%$ ocurre ulceración, que puede manifestarse como hemorragia digestiva. El tamaño varia desde pocos milímetros hasta $30 \mathrm{~cm}$. Son bien delimitados con áreas internas de hemorragia, necrosis y componente quístico. Histológicamente se dividen en tumores de células fusiformes que constituyen un $70-80 \%$ de los casos y epitelioides que corresponden al $20-30 \%$ restante.

\section{Hallazgos radiológicos}

Múltiples modalidades de estudios de imágenes se han utilizado para la detección de tumores gastrointestinales.

La radiografía de abdomen simple puede detectar una masa con densidad de partes blandas, que desplaza asas de intestino o estomago, sin embargo tiene baja sensibilidad y no puede caracterizarla en forma específica.

En los estudios baritados, como la radiografía de esófago-estomago-duodeno o el transito de intestino delgado, el hallazgo más frecuente es una masa extramucosa (Figura 1), a veces con componente pólipoideo intraluminal, con pequeñas ulceraciones, hallazgo presente en el $50-60 \%$ de los casos.

La tomografía computada (TC) en especial la con múltiples detectores es el método de elección para la caracterización de estos tumores, ya que logra alta resolución en los 3 planos (resolución isométrica); y a través de reconstrucciones multiplanares aumenta la sensibilidad para la detección del origen anatómico(5). Características habituales del tumor en la TC son: Masa intramural con componente exofítico que se proyecta hacia la cavidad abdominal (Figuras 2,3,4), bien circunscrita; que pueden
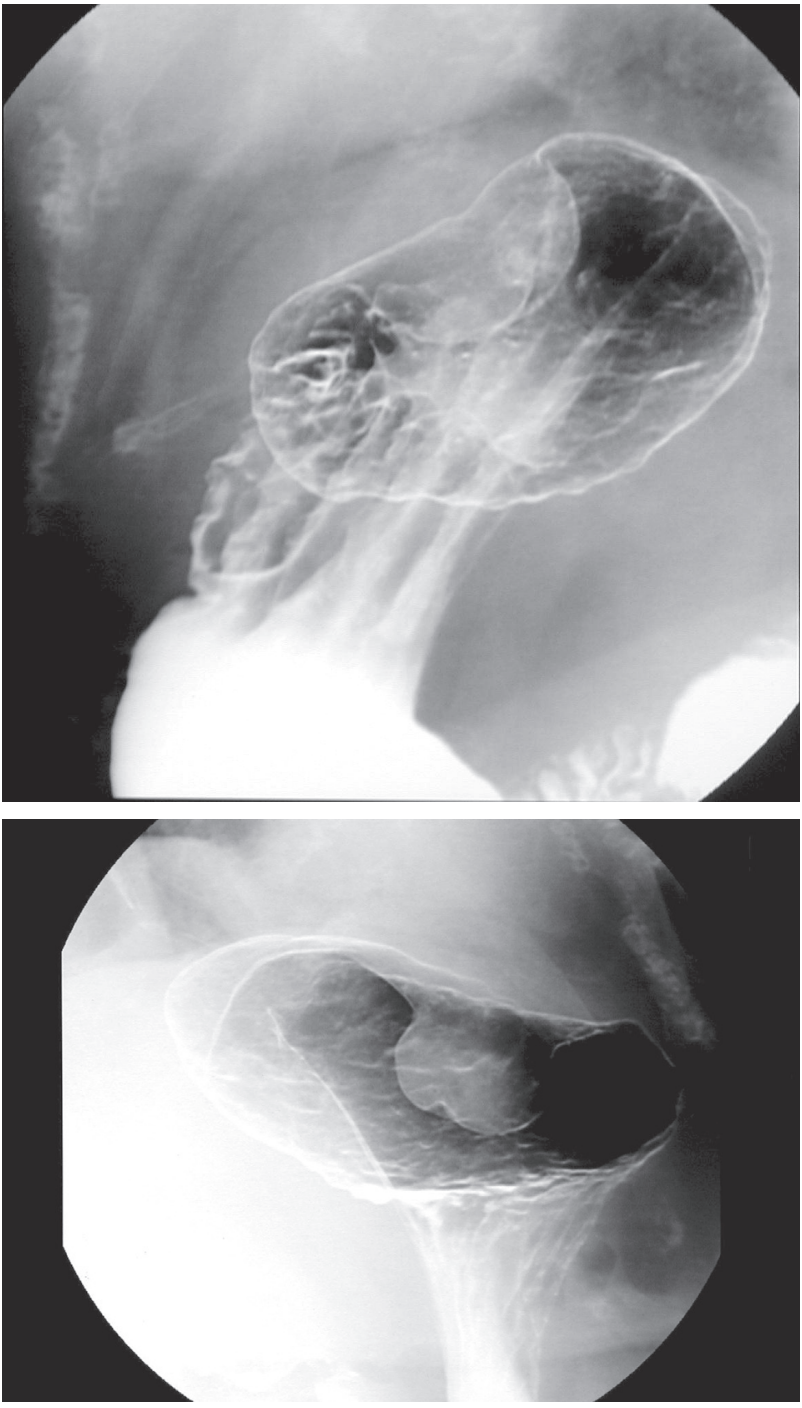

Figura 1 a,b. Estudio baritado de tubo digestivo superior que demuestra una masa submucosa del fondo gástrico, de contornos regulares.

presentar un componente polipoideo intraluminal y exofítico dando una apariencia en "reloj de arena» (Figura 5). Otro hallazgo habitual es impregnación periférica y heterogénea después del uso de medio de contraste endovenoso (Figuras 6,7). Se describen áreas de menor atenuación intralesional secundarias a necrosis, hemorragia y degeneración quística. La presencia de calci-ficaciones es inusual (Figuras 6b, 10b). En lesiones de mayor tamaño puede haber excavación (Figura 8), que establece a través de trayectos fistulosos conexión con el lumen de la víscera hueca comprometida.

Hallazgos sugerentes de malignidad son un tamaño superior a $5 \mathrm{~cm}$, invasión local, gas intratumoral por necrosis y metástasis hepáticas (Figura 9) o peritoneales.

En resonancia magnética, en secuencias ponderadas en $\mathrm{T} 1$ se detecta con mayor sensibilidad hemorragia, siendo las otras características similares a las descritas para TC. 
Dentro del diagnóstico diferencial del GIST gástrico se debe considerar el leiomioma, leiomiosarcoma, schwanoma, neurofibroma, y tumor neuroendocrino como el carcinoide. En el diagnóstico diferencial del GIST intestinal debe incluirse linfoma, que se presenta generalmente como una masa ulcerada centrada en un asa de intestino y usualmente se asocia a adenopatías, a diferencia de los GISTs que no se asocian a estas. Tumores mesentéricos que pueden simular GIST son desmoides, linfomas y metástasis. La mesenteritis esclerosante puede también constituir un diagnostico diferencial.

Los GISTs esofágicos (Figura 10), como se explicó previamente, son muy poco frecuentes, siendo sobrepasados por los leiomiomas.

Se ha descrito un caso de GIST asociado a pseudotumor hepático ${ }^{(8)}$. En la etiopatogenia se postula permeación bacteriana a nivel intestinal. Hasta la fecha no hay descrita asociación con abscesos hepáticos.

El tratamiento es la resección quirúrgica. Joensuu et al( $^{(6)}$ describió en el año 2001 un efecto positivo, estadísticamente significativo en el manejo de estos tumores con el uso de inhibidor de tirosina kinasa, STI571, en pacientes con GIST metastático.
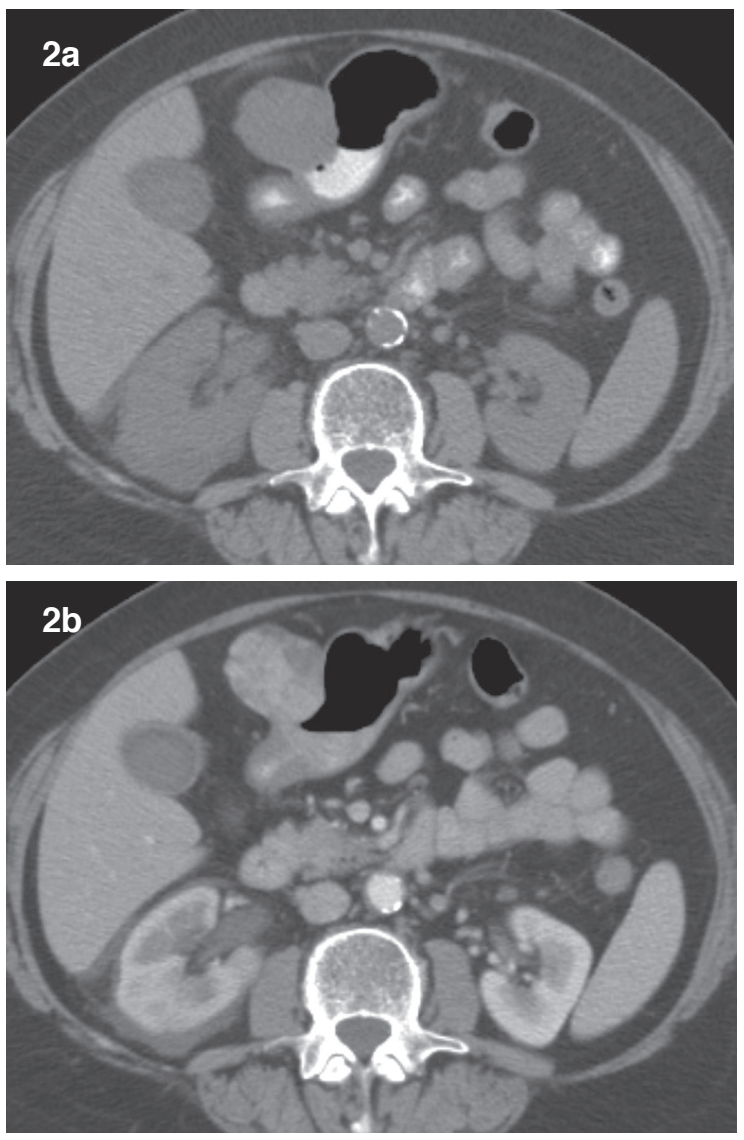

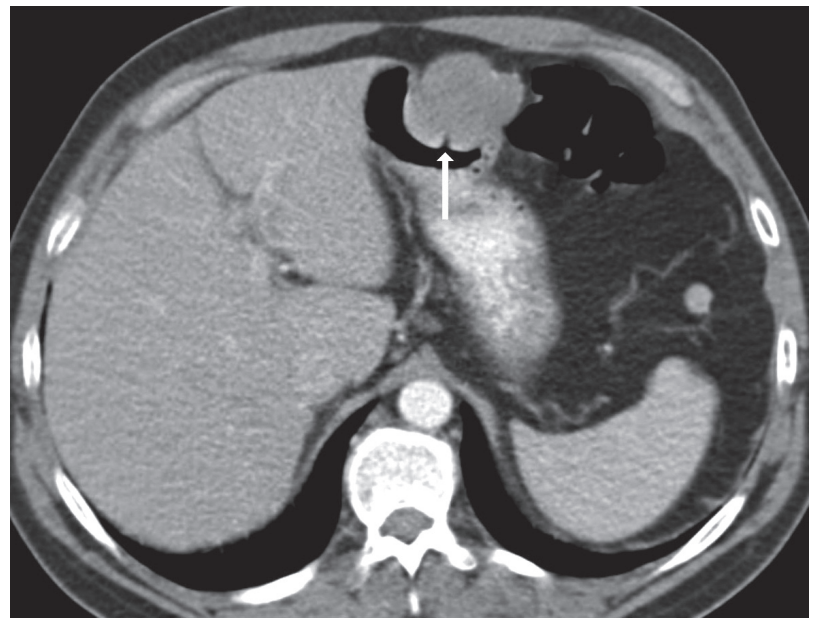

Figura 3. TC de abdomen con contraste que muestra una masa exofítica en antro gástrico con componente intraluminal submucoso y una pequeña ulceración (flecha).
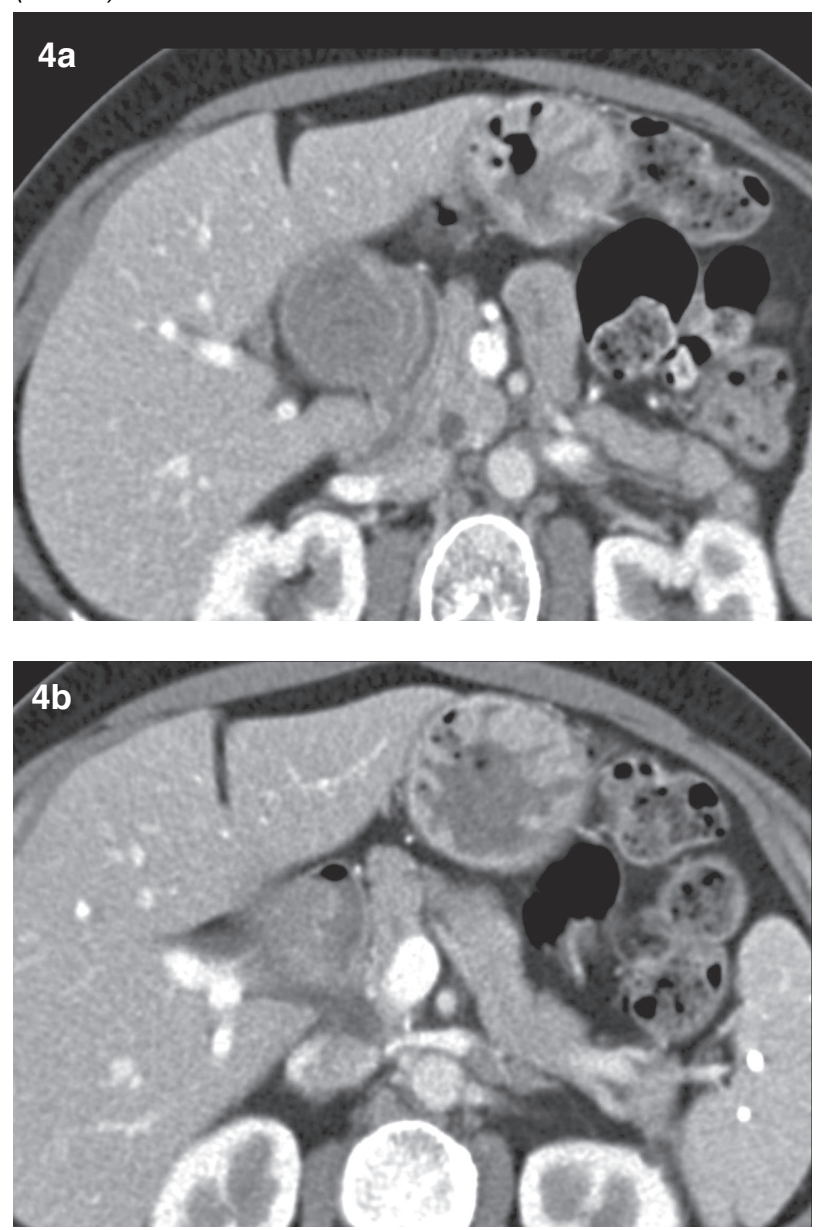

Figura 4 a,b. TC de abdomen con contraste en la cual se identifica una masa exofítica paraduodenal (a) que comprime la segunda porción del duodeno, y que se origina en su pared lateral (b).

Figura 2 a,b. TC de abdomen sin (a) y con (b) contraste yodado endovenoso. Se observa una masa exofítica a nivel del antro gástrico que se impregna en forma heterogénea con el contraste. 

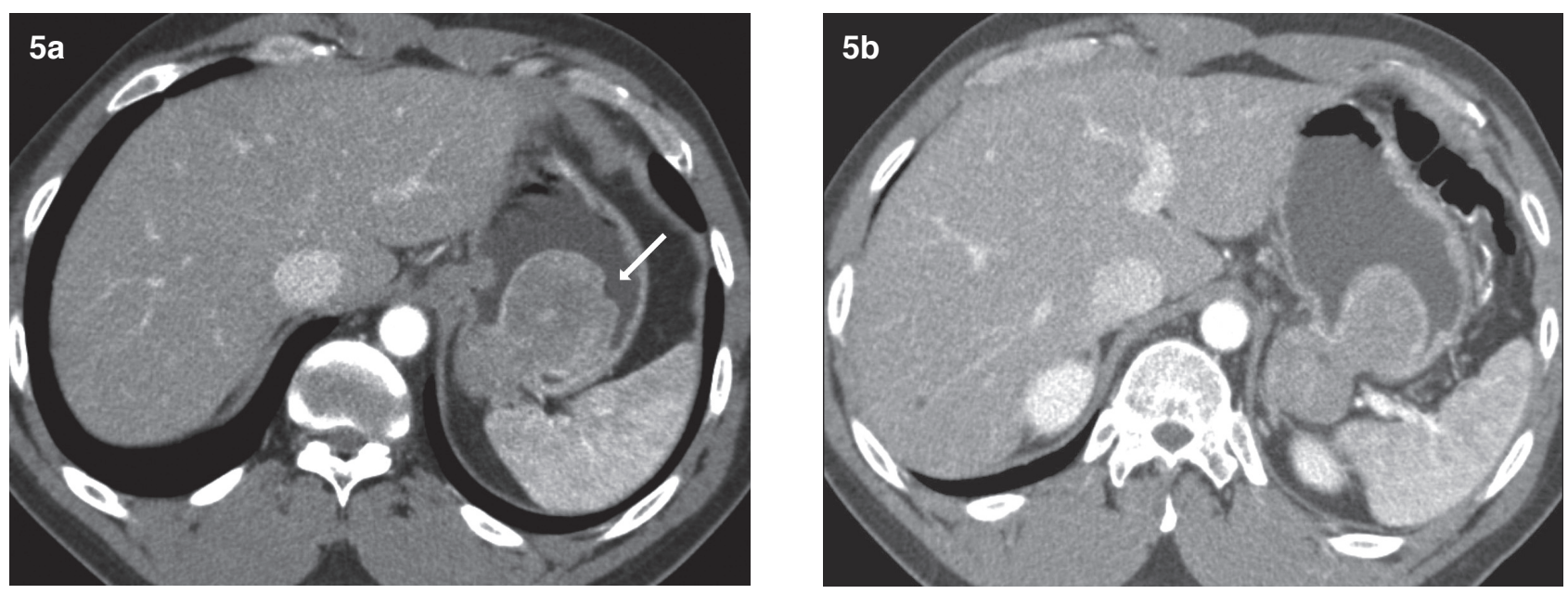

Figura 5 a,b. TC de abdomen que muestra una masa gástrica con un componente intraluminal ulcerado (a) (flecha) y uno exofítico que crece hacia la cavidad abdominal (b), adoptando una configuración en «reloj de arena».
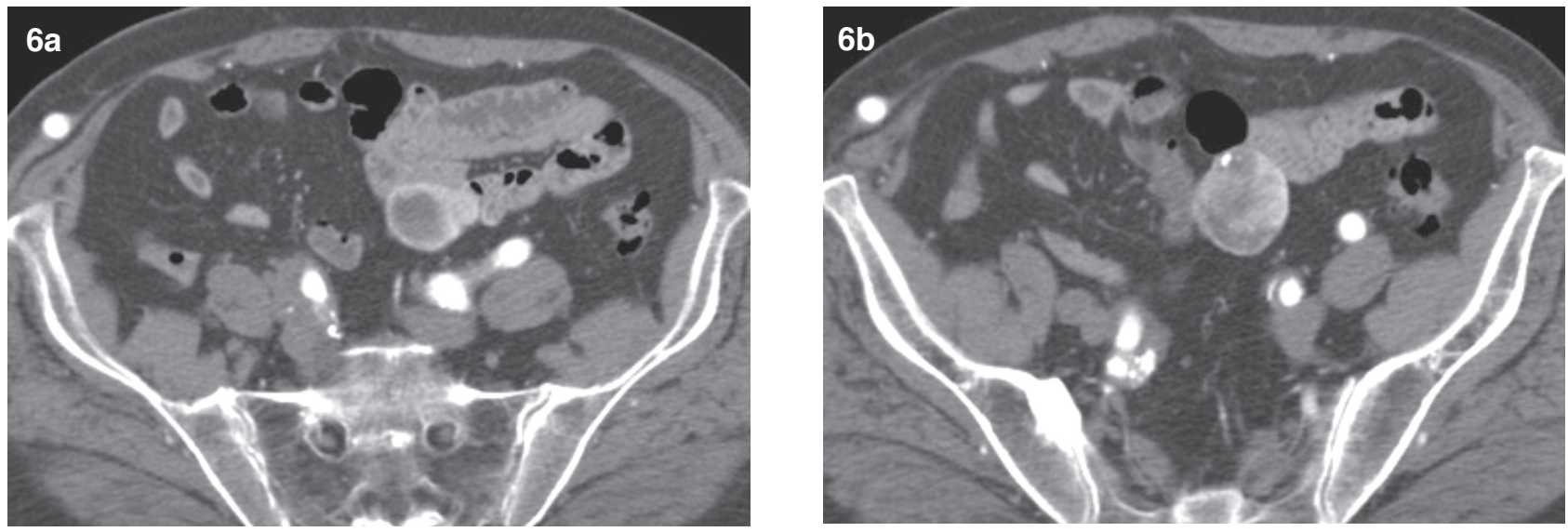

Figura 6 a,b. TC contrastado de abdomen en el que se observa una masa exofítica que contacta un asa de yeyuno distal, la que se refuerza en forma periférica (a) y heterogénea (b) asociada a pequeña calcificación.
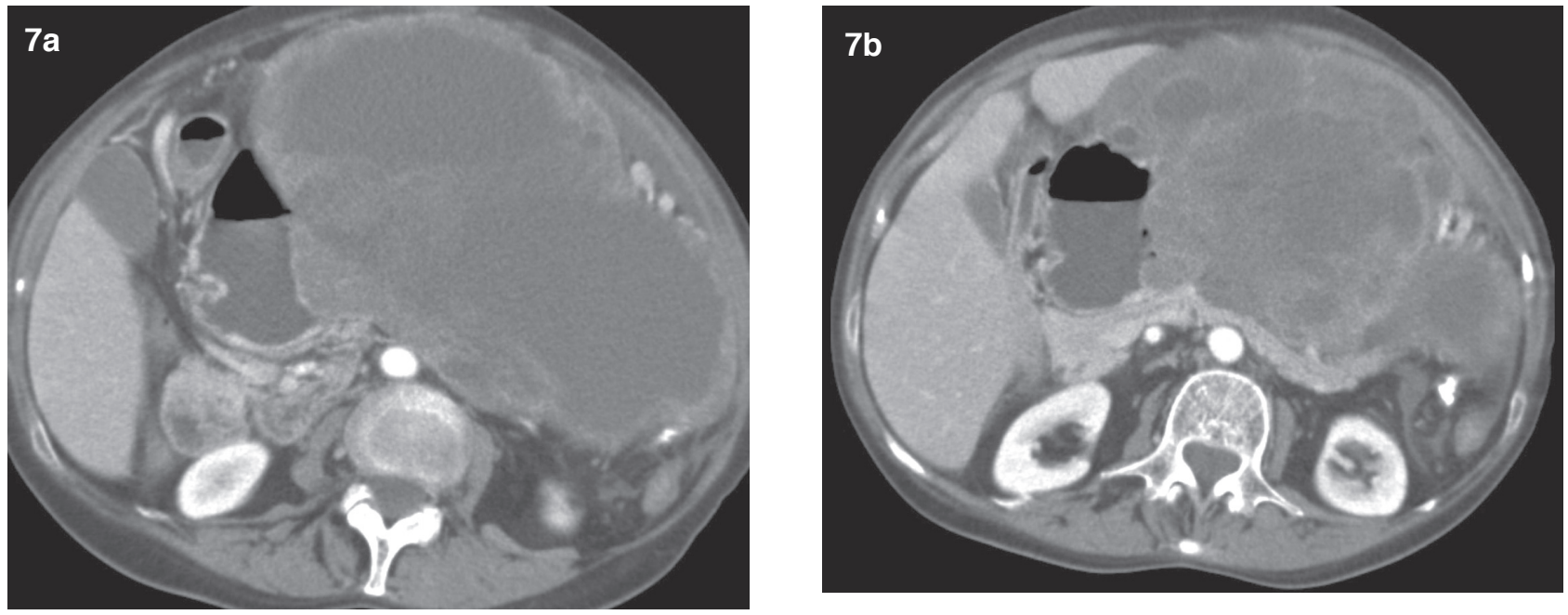

Figura 7 a,b. GIST maligno. TC con contraste que muestra una gran masa, mayor a $5 \mathrm{~cm}$, proveniente de la pared gástrica con refuerzo periférico (a) y contornos irregulares (b). 

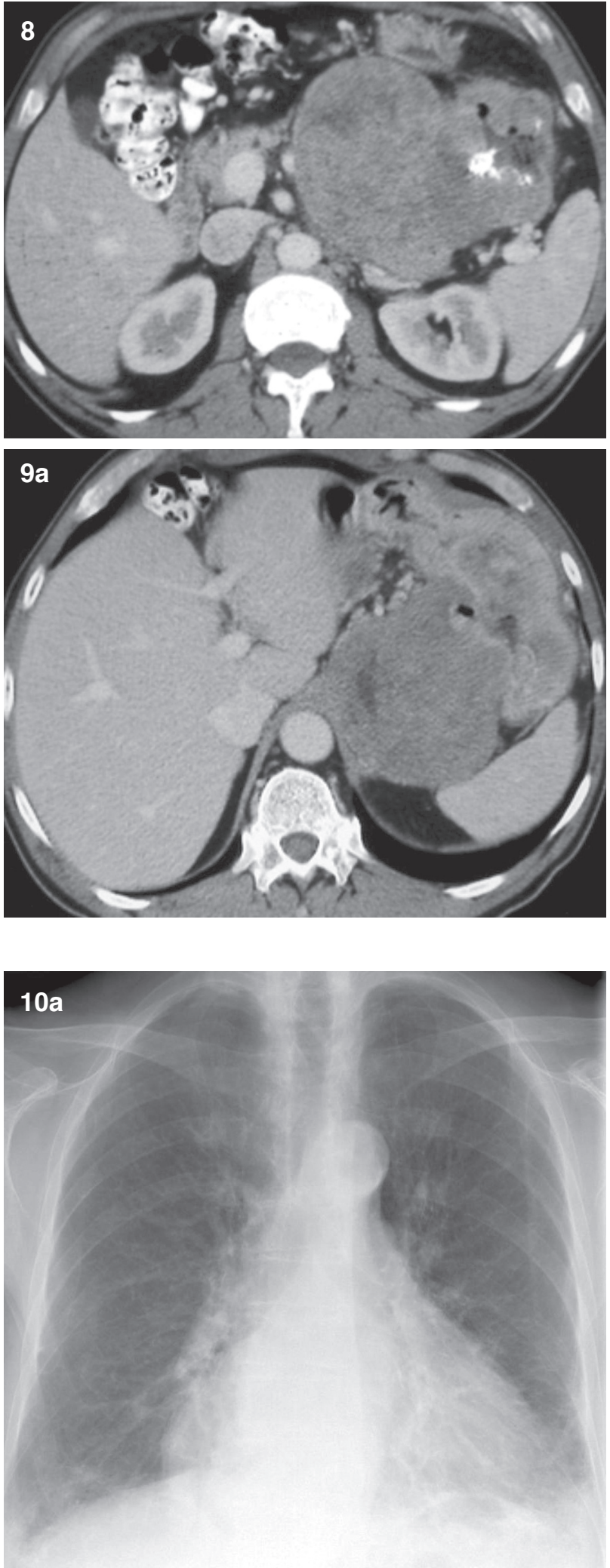

Figura 10 a-c. a: Radiografía PA de tórax que muestra obliteración del receso azigo-esofágico evidencia indirecta de una masa del mediastino posterior. b, c: TC con contraste endovenoso confirma una masa en mediastino posterior, sólida, heterogénea con fina calcificación interior, que se origina en la pared lateral izquierda del tercio distal del esófago al que desplaza.
Figura 8. GIST maligno. TC contrastado que evidencia una gran masa infiltrante gástrica con área de excavación en la cual se deposita el contraste oral.

Figura 9 a,b. GIST maligno. TC con contraste en la que se observa una gran masa infiltrante gástrica (a) asociada a múltiples metástasis hepáticas (b).
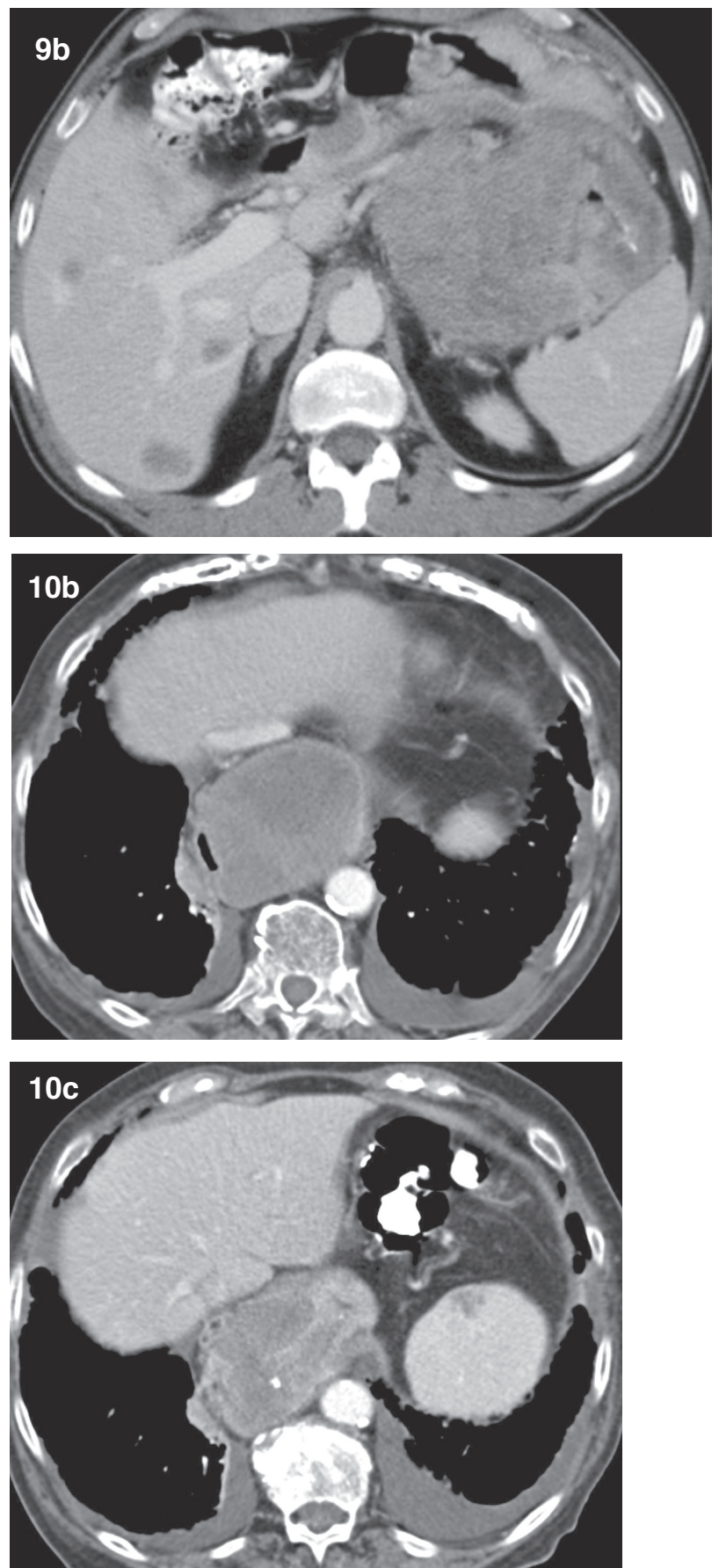


\section{Conclusión}

Los GISTs son los tumores mesenquimáticos más frecuentes del tracto gastro-intestinal, caracterizados por la expresión en el $100 \%$ de la proteína CD117 a la inmuno-histoquimica, lo que los diferencia de otros tumores mesenquimáticos de este sistema. Se pueden localizar en cualquier porción del tracto digestivo, omento o mesenterio, sin embargo, la mayoría se localizan en el estómago y presentan comportamiento benigno.

En TC, se caracterizan por ser exofíticos, bien delimitados, con un componente extramucoso que puede ser detectado en estudios baritados. Signos de malignidad incluyen un tamaño superior a $5 \mathrm{~cm}$, la localización extragástrica, un alto índice mitótico, la invasión local y la presencia de metástasis hepáticas o peritoneales.

El uso de inhibidor de tirosina kinasa puede ser prometedor en el tratamiento de esta enfermedad, en especial en compromiso avanzado.

\section{Bibliografía}

1. Levy A, Remotti H, Thompson W et al. M. From the Archives of the AFIP: Gastrointestinal Stromal
Tumors. Radiologic features with pathologic correlation. Radiographics 2003; 23: 283-304.

2. Sharp R, Ansel H, Keel S. Best cases from the AFIP: Gastrointestinal Stromal Tumor. Radiographics 2001; 21: 1557-1560.

3. Burkill G, Badran M, Al-Muderis $\mathrm{O}$ et al. Malignant GIST: Distribution, imaging features and pattern of metastatic spread. Radiology 2003; 226: 527-532.

4. Ba-Ssalanah A, Prokop M, Uffmann $M$ et al. Dedicated multidetector CT of the stomach: Spectrum of diseases. Radiographics 2003; 23: 625-644.

5. Horton K, Fishman E. Current role of CT in imaging of stomach. Radiographics 2003; 23: 75-87.

6. Joensuu HR, Roberts PJ, Sarlomo-Pikala M et al. Effect of Tyrosine Kinase Inhibitor STI571 in patient with a metastatic gastrointestinal stromal tumor. N Engl J Med 2001; 344: 1052-1056.

7. Soza F, López A, Arancibia G. GIST, tumor estromal gástrico. Rev Chil Radiol 2001; 7: 116,140-141.

8. Lo OS, Poon RT, Lam CM, Fam ST. Inflammatory pseudotumor of the liver in association with a gastrointestinal stromal tumor: A case report. World J Gastroenterol 2004; 10: 1841-1843.

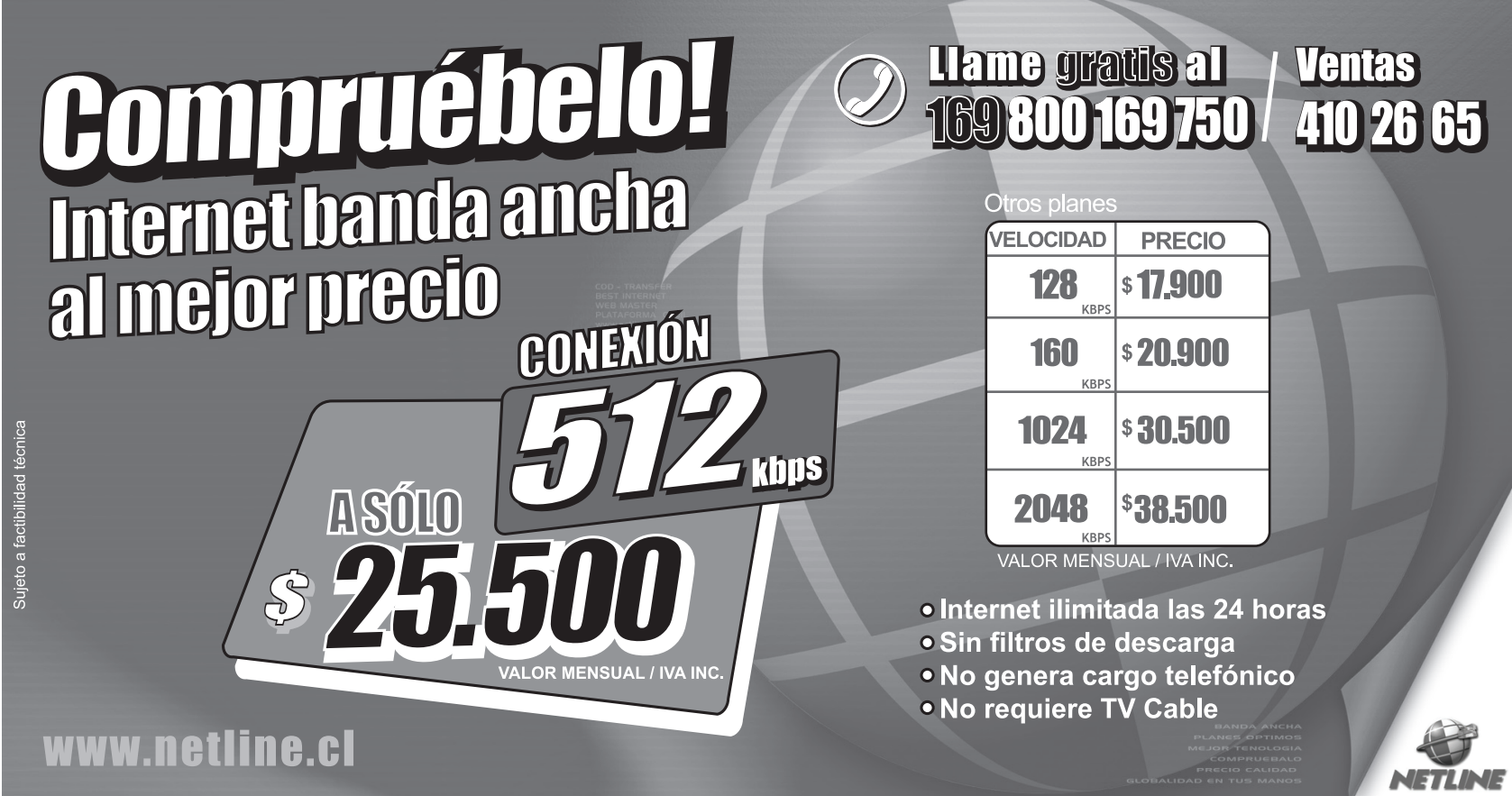

